\title{
Study of Medical Interns' Knowledge Level About Children's Oral Health Between 2011 and 2012 in Medical Universities in Tehran, Iran
}

\author{
Alireza Fahimzad ${ }^{1}$; Mohammad Nasiri ${ }^{2, *}$; Hosein Heydari ${ }^{3}$; Fatemeh Sadat Sarfjoo ${ }^{4}$ \\ ${ }_{1}^{1}$ Pediatric Infections Research Center, Mofid Children's Hospital, Shahid Beheshti University of Medical Sciences, Tehran, IR Iran \\ ${ }_{3}^{2}$ Pediatric Intensive Care Unit, Mofid children's Hospital, Shahid Beheshti University of Medical Sciences, Tehran, IR Iran \\ 3 Pediatric Medicine Research Center, Qom University of Medical Sciences, Qom, IR Iran \\ ${ }_{4}^{4}$ Pediatric Medicine Research Center, Qom University of Medical Sciences, Qom, IR Iran
${ }^{2}$ epartment of Obstetrics and Gynecology, Shahid Beheshti University of Medical Sciences, Tehran, IR Iran \\ *Corresponding author: Mohammad Nasiri, Pediatric Intensive Care Unit, Mofid children's Hospital, Shahid Beheshti University of Medical Sciences, Tehran, IR Iran. Tel: +98- \\ 219121763489, Fax:+98-2122227033, E-mail: moham.nasiri@gmail.com
}

Received: June 8, 2014; Revised: October 24, 2014; Accepted: May 10, 2015

\begin{abstract}
Background: There are several oral problems in pediatrics relating to normal general health. The most common problems are tooth decay and periodontal disease.

Objectives: This study was conducted to evaluate medical interns' knowledge about oral/dental problems in educational hospitals affiliated to the medical universities in Tehran.

Materials and Methods: In this cross-sectional descriptive study, conducted between 2011 and 2012, 391 educational hospital interns from medical universities of Tehran, Shahid Beheshti, Iran, and Islamic Azad were included. The data, collected via questionnaires, were analyzed through descriptive statistics and central index tests.

Results: In this study, the average age of the interns was 25.18 (standard deviation (SD) $=1.25$ years). Males accounted for $44.2 \%$ of the study population, and the rest were female. The average score of the interns' knowledge level was 4.87 from a maximum of $15(\mathrm{SD}=1.73)$. Age, sex, and duration of education did not have any effect on the level of knowledge.

Conclusions: According to this study, it seems that the educational hospital interns do not have enough essential information and knowledge about pediatric oral/dental health. Therefore, it is recommended to incorporate new learning programs about pediatric oral/ dental health in their curricula.
\end{abstract}

Keywords: Students Medical; Pediatrics; Oral Medicine; Dental Health Services

\section{Background}

Children may have several oral problems which impact their lifestyle, health, sense of well-being, and natural function. The most common problems are dental caries and periodontal conditions. The prevalence of dental caries and gingivitis in Iranian teenagers has been reported to exceed $60 \%$ and $95 \%$, respectively (1). These problems may lead to odontalgia, gingival bleeding, tooth loss, unpleasant appearance, and disruption to daily activities. Despite the advances in dental sciences in the last century, the frequency and prevalence of dental caries, which are the most common pediatric dental illnesses, have increased in developing countries over the last 20 years (2). These problems are associated with increasing preventive and medical movements, ranging from simple interventions such as early diagnosis, mouth wash, and dental health instructions to sophisticated management modalities, all of which impose huge financial burdens on governments. Promoting health care programs for controlling and improving oral health indices is a combination of instruction and prevention activities (1). Lewis et al. studied the role of dentists in pediatric oral health and reported that the competence of general practitioners and pediatricians plays a unique role at well-child care visits to provide caries prevention (3). Krol et al. studied oral dental health instructions within general practitioners' course and found out that since this subject is not taught in medical science universities, minimal knowledge of oral/dental problems should be included in the curriculum (4). Bader et al. conducted some research into practitioners' role in preventing teeth problems in preprimary school children. They found that although dental caries is preventable, this prevention should be started in medical offices because the rate of children's referral to practitioners is higher than their referral to dentists (5). Parents usually lack adequate information about the importance of teeth health and referring their children to dentists, which results in increasing tooth decay and oral health problems. Children are teachable, and teaching them is believed to increase their knowledge up to $50 \%(6-8)$. There are some efforts that should be made by parents such as teaching and supervising accurate tooth brushing at appropriate age $(9,10)$. There are a limited

Copyright (C) 2015, Pediartric Infections Research Center. This is an open-access article distributed under the terms of the Creative Commons Attribution-NonCommercial 4.0 International License (http://creativecommons.org/licenses/by-nc/4.0/) which permits copy and redistribute the material just in noncommercial usages, provided the original work is properly cited. 
number of studies about practitioners' knowledge about oral/dental health and preventive programs. The way physicians and dentists view preventive programs about oral/dental problems is of great importance (11).

\section{Objectives}

We examined medical interns' knowledge level about pediatric oral/dental health in Tehran between 2011 and 2012 to introduce the necessity of practitioners' education about this issue.

\section{Materials and Methods}

The sample population of this descriptive cross-sectional study, conducted between 2011 and 2012, consisted of 391 medical interns who were selected randomly from Tehran university of medical sciences, Shahid Beheshti university of medical sciences, Iran university of medical sciences, and Islamic Azad university in Tehran. Data were collected on pediatric oral/dental health through a selfadministered valid questionnaire. First, 446 questionnaires were filled in by the interns. After the exclusion of the incomplete ones, 391 questionnaires were evaluated statistically. The questionnaires comprised three demographic and fifteen knowledge-survey questions. The questions were about pediatric oral/dental health, tooth brushing methods, time of dental visits, fluoride affects, and tooth development. The validity of the questionnaire was confirmed based on related surveys and guidance from dental university professors, and a pilot study was carried out to confirm its reliability. A score of 1 was allocated to each correct answer, and then the sum of the correct answers was calculated.

The data were analyzed using IBM statistical package for the social sciences (SPSS) (SPSS Inc. Released 2008. SPSS Statistics for Windows, Version 17.0. Chicago: SPSS Inc.) as well as the independent T-test and the chi-square test. A P value of 0.05 was considered statistically significant.

\section{Results}

The sample size in our study was 391 interns, comprised of 218 females and 173 males. The frequency percentages of the females and males were $55.8 \%$ and $44.2 \%$, respectively. The mean score was 4.91 for the females and 4.82 for the males. There were no significant statistical differences between the two groups, while the mean score for the interns, regardless of gender, was $4.87(\mathrm{SD}=1.73$ ). In addition, the minimal score was zero, and the maximum score was 15 (Figure 1). The mean score for the age of the interns was 25.18 (SD = 1.25). There were no statistically significant differences between the interns' age and their knowledge level (P $>0.05$ ). Four interns had a short dental course, but the mean score for the instructed interns was 5 , while it was 4.87 for the non-instructed ones. There were no significant differences between the two groups.
Figure 1. Frequency of Interns' Correct Responses in Each Question of the Questionnaire

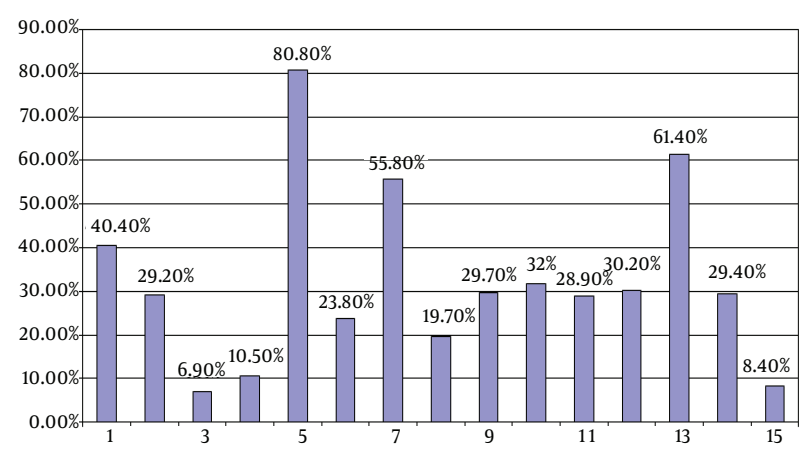

The x-axis stands for the number of questions. There were 15 questions in each questionnaire.

\section{Discussion}

Medical interns will have the closest relationship with children and their families as general practitioners in the future and, as such, need to have appropriate knowledge about children's oral/dental health. Based on our findings, the interns' knowledge level about oral/dental health in Tehran, Iran, between 2011 and 2012 was low and the variables of age, gender, and period of instruction had no effect on their knowledge level. Our review of the medical curriculum in Shahid Beheshti and other universities of medical sciences showed that oral/dental health education does not receive enough attention. Similarly, our evaluation of the curricula in developed countries also revealed an obvious inadequate attention to this issue in the education systems. A research carried out by the residency review committee (RCC) on pediatric residency indicated that there was poor motivation to teach oral health (12). In addition, The Association of American medical college curriculum (AAMC) found that there was no oral health credit in the curriculum of the medical universities in the United States (13). Prakash et al. examined the knowledge level of general practitioners and pediatricians about oral/dental health in Toronto, Canada, and showed that while the majority of the pediatricians and family physicians reported aspects of oral health in well-child care visits, a lack of dental knowledge and training appeared to preclude these physicians from playing a more active role in promoting the oral health of children in their practices (14). Dela Cruz et al. studied the screening and referral of children to dentists and reported that although practitioners chose the appropriate approach toward the prevention of oral problems, they referred children to dentists improperly (15). Pierce et al. conducted a 2-hour instruction course for practitioners, and their findings showed 
Fahimzad A et al.

that the practitioners diagnosed 70\% of children with oral/dental health problems and referred them to dentists. Therefore, sufficient instruction, even for a short time, may increase practitioners' discernment (16). In another study, McCunniff et al. found that the number of children referred to dentists by their practitioners was twice as many as children who were not referred to dentists (17). Elsewhere, Herndon et al. examined the knowledge level of general practitioners and pediatricians about the oral/dental health of children and demonstrated that the knowledge level in the general practitioners was relatively lower than that in the pediatricians (18). Bottenberg et al. found out that $71 \%$ of pediatricians had relative knowledge about oral/dental health (19). Based on these findings, it seemed necessary to bring to bear a special focus on the educational program of pediatricians. Hatami et al. examined the knowledge level of general practitioners about children's oral/ dental health in Tehran, Iran, during 2010 and showed that $34.8 \%$ of them had insufficient knowledge. The mean score obtained in this study was low, as well (20). We faced some difficulties in conducting the present study, first and foremost among which was reluctance on the part of the medical interns to fill in the questionnaire. It is highly likely that they do not appreciate the significance of children's oral/dental health and its relation with their practice.

The results obtained from this study and other similar studies indicate that the knowledge level of medical interns about children's oral/dental health is far from sufficient. However, it seems necessary to conduct more studies and researches to determine factors which are effective in enhancing their knowledge. We suggest that workshops be held within internship courses and some training credits be added to medical interns' curricula so as to address this shortcoming and promote oral/ dental health in children.

\section{Acknowledgements}

We would like to express grateful thanks to Shahid Beheshti university of medical sciences for supporting the project and to the statistician for analyzing the data. Our special thanks to Dr. Mohammad-Hussein Khoshnevisan PhD, DMD, DPHDent, DrPH, assistant professor and head of the department of community oral health and director of the preventive dentistry research centre, Shahid Beheshti university of medical sciences, Tehran, Iran, for his expert opinions.

\section{Authors' Contributions}

1- Study concept and design: Dr. Fahimzad and Dr. Nasiri, 2- Acquisition of data: Dr. Nasiri, 3- Analysis and interpretation of data: Dr. Fahimzad, Dr. Nasiri, and Dr. Hidari 4- Drafting of the manuscript: Dr. Nasiri 5- Critical revision of the manuscript for important intellectual content: Dr. Fahimzad, 6- Statistical analysis: Dr. Hidari
7- Administrative, technical, and material support: Dr. Fahimzad, Dr. Nasiri, and Dr. Hidari 8- Study supervision: Dr. Fahimzad and Dr. Nasiri.

\section{References}

1. Yunesian F, Saffar Shahroodi A, Kavand G. Quality of life related to oral health in pediatric 11 to 14 years of Iran by the Child-OIDP: Part II - Social effects - Dental (Socio-dental impacts) periodontal disease and caries. J Dent School Shahid Beheshti Univ Med Sci. 2000;28(4):225-31.

2. Mosahab P. , Kargar Novin Z, Malek Afzali B, et al. . The relationship between dental caries and receive food in a group of Iranian pediatric in 1388. J Dent Sci Res. 2000;7(4):42-50.

3. Lewis CW, Grossman DC, Domoto PK, Deyo RA. The Role of the Pediatrician in the Oral Health of Children: A National Survey. Pediatrics. 2000;106(6):e84

4. Krol DM. Educating Pediatricians on Children's Oral Health: Past, Present, and Future. Pediatrics. 2004;113(5):e487-e92.

5. Bader JD, Rozier RG, Lohr KN, Frame PS. Physicians' roles in preventing dental caries in preschool children: a summary of the evidence for the U.S. Preventive Services Task Force. Am J Prev Med. 2004;26(4):315-25.

6. Assink MH, Verhey JG, Hoogstraten J, Goedhart H. Perception of dental and other individual problems: adolescents versus young adults. Community Dent Oral Epidemiol. 1995;23(6):369-73.

7. Worthington HV, Hill KB, Mooney J, Hamilton FA, Blinkhorn AS. A cluster randomized controlled trial of a dental health education program for 10-year-old children.J Public Health Dent. 2001;61(1):22-7.

8. Pollick HF, Rice AJ, Echenberg D. Dental health of recent immigrant children in the Newcomer schools, San Francisco. Am JPublic Health. 1987;77(6):731-2

9. Verrips GH, Kalsbeek H, Frencken JE, ter Horst G, Filedt KokWeimar TL. [Caries in children from ethnic groups. An investigation in five-year-old children in Amsterdam and their parents concerning risk indicators and factors]. Ned Tijdschr Tandheelkd. 1993;100(2):71-4.

10. Blinkhorn AS, Wainwright-Stringer YM, Holloway PJ. Dental health knowledge and attitudes of regularly attending mothers of high-risk, pre-school children. Int Dent J. 2001;51(6):435-8.

11. Di Giuseppe G, Nobile CG, Marinelli A, Angelillo IF. Knowledge, attitude and practices of pediatricians regarding the prevention of oral diseases in Italy. BMC Public Health. 2006;6:176.

12. Accreditation Council for Graduate Medical Education. . Program Requirements for Residency Education in Internal Medicine. Chicago; 2009.

13. Association of American Medical College Curriculum Directory. Available at: www.aamc.org.

14. Prakash P, Lawrence HP, Harvey BJ, McIsaac WJ, Limeback H, Leake JL. Early childhood caries and infant oral health: Paediatricians' and family physicians' knowledge, practices and training. Paediatr Child Health. 2006;11(3):151-7.

15. Dela Cruz GG, Rozier RG, Slade G. Dental screening and referral of young children by pediatric primary care providers. Pediatrics. 2004;114(5):e642-52.

16. Pierce KM, Rozier RG, Vann WF. Accuracy of Pediatric Primary Care Providers' Screening and Referral for Early Childhood Caries. Pediatrics. 2002;109(5):e82.

17. McCunniff MD, Damiano PC, Kanellis MJ, Levy SM. The impact of WIC dental screenings and referrals on utilization of dental services among low-income children. Pediatr Dent.1998;20(3):181-7.

18. Herndon JB, Tomar SL, Lossius MN, Catalanotto FA. Preventive oral health care in early childhood: knowledge, confidence, and practices of pediatricians and family physicians in Florida.J Pediatr. 2010;157(6):1018-1024 e1-2.

19. Bottenberg P, Van Melckebeke L, Louckx F, Vandenplas Y. Knowledge of Flemish paediatricians about children's oral health-results of a survey. Acta Paediatr. 2008;97(7):959-63.

20. Hatami HMLM. . study knowledge of general physician about pediatrics teeth and mouth health.. Tehran: Shahid Beheshti University of Medicin; 2000. 